\title{
Finite element modeling and random vibration analysis of BGA electronic package soldered using lead free solder alloy - Sn-1Cu-1Ni-1Ag
}

\author{
S. Jayesh ${ }^{*}$ and J. Elias \\ Department of Mechanical Engineering, School of Engineering, Cochin University of Science and Technology, Kerala 682022, \\ India
}

Received: 17 May 2019 / Accepted: 13 June 2019

\begin{abstract}
As a result of the ban of lead from solder joints, many lead-free solder joints were developed. Most of the electronic equipment is subjected to random vibration. This study develops an analysis methodology based on finite element analysis and vibration tests to predict the failure and fatigue life of the electronic package soldered using $\mathrm{Sn}-1 \mathrm{Cu}-1 \mathrm{Ni}-1 \mathrm{Ag}$ under random vibration. A specially designed printed circuit board having ball grid array packages soldered is used in the study. Finite element model is developed in ANSYS and modal analysis was done. The finite element results were validated with experiments (impact test). Random vibration analysis was also done. These results were validated with random vibration experiments. Using the finite element results, it was predicted that the corner solder joints will fail first. It was observed in the random vibration experiment that corner solder joint failed first and the maximum stress generated was $12.8 \mathrm{MPa}$. Thus, $\mathrm{Sn}-1 \mathrm{Cu}-1 \mathrm{Ni}-1 \mathrm{Ag}$ is a promising lead-free solder joint alloy under random vibration combining with its mechanical properties.
\end{abstract}

Keywords: Random vibration / modal analysis / lead free / solder alloy / finite element analysis / simulation

\section{Introduction}

Soldering is a very old metallurgical joining method in which two or more metals are joined without melting the parent metals, but by melting and flowing a filler metal (solder) into the joint, also the melting temperature will be less than $315^{\circ} \mathrm{C}[1,2]$. The traditional lead containing $\mathrm{Sn}-\mathrm{Pb}$ solder alloy was banned due to the inherent toxicity of the lead and the environmental legislations like RoHS (Restrictions on Hazardous Substances) and WEEE (Waste Electrical and Electronic Equipment) [3]. As a result $\mathrm{Pb}$ cannot be a component in the solder alloy. The researchers around the globe started research for making new lead-free solder alloys which can be used in place of Sn$\mathrm{Pb}$ solder alloy. Many solder alloys were discovered during these years [4-7]. Most of the research has focused on the failure mechanism and fatigue life prediction under thermal loads. When compared to thermal fatigue studies, less number of studies were conducted in the area of electronic packages. Most electronic components and electronic packages are exposed to random vibration

\footnotetext{
* e-mail: jayesh.jhe@gmail.com
}

environment [8]. With the rise of portable electronics, relevance of drop/shock impact has increased. The mobile phones used today have high chance to expose to random vibration at different conditions. Subject to vibration loading, vibration-induced failure is the most common failure modes in avionic and automotive electronic systems, where a huge amount of vibrations are produced during their service life. Most of the electronic systems are exposed to random vibrations rather than ordinary harmonic loads [9]. The higher order Haar wavelet method (HOHWM) utilized for random vibration analysis of nanobeams and the results obtained were compared with widely used HWM (Haar wavelet method) [10]. The properties of a small-scale bridge (irregular) and its dynamic tests have been discussed in another study. A linear analytical model with viscous model is proposed in this study to reproduce the response of the model to medium intensity excitations [11]. In another study, the dynamic behavior of the fixtured workpiece subjected to time-and space-varying machining loads is simulated using a forced vibration model [12]. Topology optimization of structures with damping that is exposed to harmonic force excitation with prearranged frequency higher than its natural resonance frequency is done in another study [13]. 


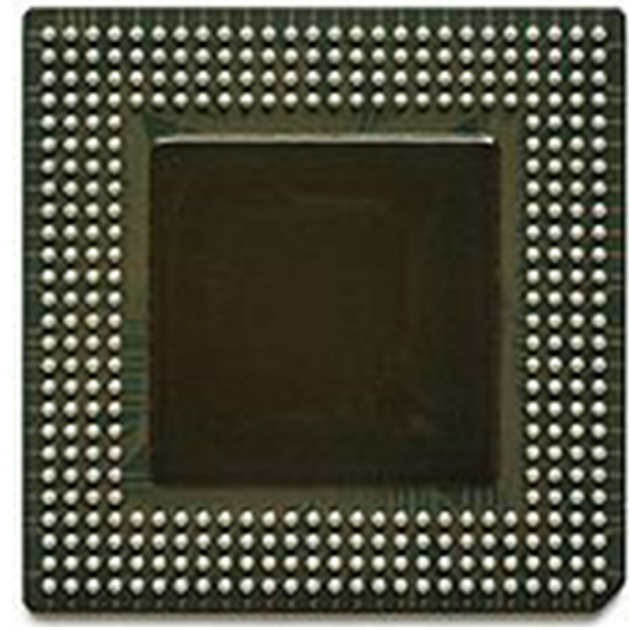

Fig. 1. The bottom view of an Intel Embedded Pentium MMX.

The function of the electronic package is to make the Integrated Circuit (IC) safe from electrical, mechanical, chemical and thermal harm. It also provides interconnections to other devices [1]. According to Moore's law, the transistor density of integrated circuit will double in every 18 months [14]. As a result of this, the functioning becomes more complex and difficult. Citing an example, there were 2250 transistors in Intel's 4004 chip. Intel Itanium 2 processor in 2003 had 410 million transistors. The increase in the number of transistors is directly proportional to the number of interconnections from chip to the substrate. The electronic package industry should develop to incorporate this complexity. The interconnections were put underneath the package by the introduction of Ball Grid Array (BGA) in 1990s [15]. Figure 1 shows the bottom view of an Intel Embedded Pentium MMX, showing the blobs of solder. Integrated circuits (IC) are surmounted in the package using BGA which is a type of surface-mount packaging. Microprocessors are permanently mounted using BGA packages. The advantage of BGA package is that the whole bottom surface of the device can be used instead of just the perimeter. This process is done by automated processes $[16,17]$. The device is placed on a PCB with copper pads in a pattern that matches the solder balls. The assembly is then heated, either in a reflow oven or by an infrared heater, melting the balls [18]. Surface tension causes the molten solder to hold the package in alignment with the circuit board, at the correct separation distance, while the solder cools and solidifies, forming soldered connections between the device and the PCB. High density, heat conduction and low-inductance are the advantages of BGA $[16,17,19]$. In this study electronic package with BGA is selected. Leadfree solder alloys $\mathrm{Sn}-1 \mathrm{Cu}-1 \mathrm{Ni}-1 \mathrm{Ag}$ and $\mathrm{Sn}-0.5 \mathrm{Cu}-3 \mathrm{Bi}-1 \mathrm{Ag}$ are two new lead-free solder alloy materials [20,21]. Analysis of $\mathrm{Sn}-1 \mathrm{Cu}-1 \mathrm{Ni}-1 \mathrm{Ag}$ is done in this study. Modal analysis is done using finite element method and is validated by conducting the impact test experiment. Random vibration analysis is conducted using finite element method and is validated using experiments.

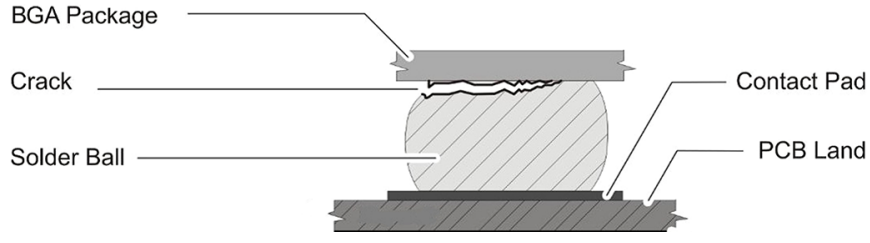

Fig. 2. Image of a solder ball.

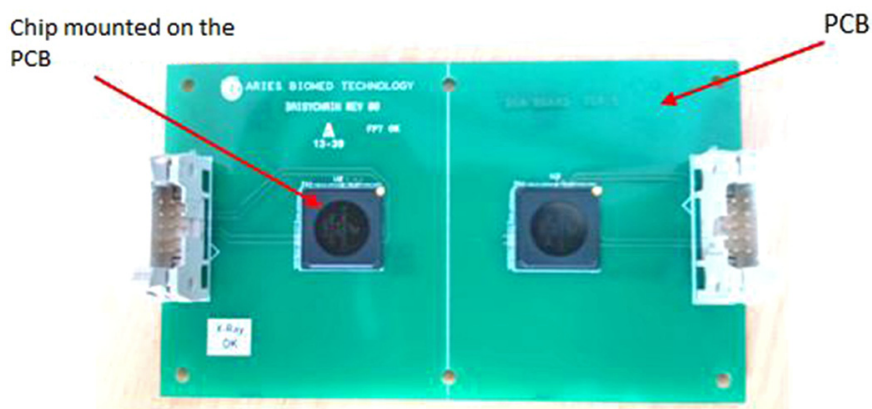

Fig. 3. PCB with two chips mounted on itage of a solder ball.

\section{Methods and experiments}

\subsection{Components and instruments}

The PCB of the electronic package under test is made of FR-4 material on which two MCIM $\times 53 \times$ D electronic chip packages are mounted by BGA balls. The solder balls are electrically connected through daisy chain circuits. Image of a solder ball is shown in Figure 2. The device is used in applications such as tablets, smart books, netbooks, net tops, internet monitors and high end mobile internet devices (MID) etc. The BGA components are designed with a daisy chain circuit, in which there are 529 lead-free solder balls that are made of a $\mathrm{Sn}-1 \mathrm{Cu}-1 \mathrm{Ni}-1 \mathrm{Ag}$. PCB with two chips mounted on it is shown in Figure 3.

\subsection{Experimental set up}

Vibration loads are given as input to the package using the vibration system which consists of Electro Dynamic Shaker, Cooling Blower, Digital Power Amplifier, Digital Control Unit, Power Module and Impact hammer. The response output vibrations are measured using Data Acquisition Card (DAQ), PC based 4-Channel ADSP Controller, Accelerometer with cables. The specifications of the components used is shown in Table 1.

\subsection{Dimensional details}

The Printed Circuit Board is $1 \mathrm{~mm}$ thick rectangular board whose dimensions are $133 \times 77 \mathrm{~mm}$. The board is made up of FR 4 material. There are 6 holes on the board which is used to secure the board on the support plate using standoffs. There are 2 BGA packages mounted on the 
Table 1. Specifications of the components used in the study.

\begin{tabular}{|c|c|c|}
\hline Sl. No. & Component & Specifications \\
\hline 1 & $\begin{array}{l}\text { Electro dynamic } \\
\text { shaker }\end{array}$ & $\begin{array}{l}\text { Model: DS-100, Armature Diameter: } 125 \mathrm{~mm} \text { Force Sine: } 100 \mathrm{kgf} \text { (Peak) Random: } \\
70 \mathrm{kgf}(\mathrm{rms}) \text { Shock: } 100 \mathrm{kgf} \text {, Mass of armature: } 1.5 \mathrm{~kg} \text {, Max acceleration: } 75 \text { 'g' } \\
\text { (Sine) Max velocity: } 1600 \mathrm{~mm} / \mathrm{s} \text {, Frequency range: } 5 \text { to } 4000 \mathrm{~Hz} \text {, Cooling: Forced } \\
\text { air, Duty: Continuous, Payload capacity: } 15 \mathrm{~kg} \text {, Armature resonance: } 3500 \mathrm{~Hz} \\
(+/-5 \%) \text {, Max. displacement: } 18 \mathrm{~mm}(\mathrm{p}-\mathrm{p}) \text { continuous, Protections: Field fail, } \\
\text { over travel, cooling interlock, over temp. }\end{array}$ \\
\hline 2 & Accelerometer & $\begin{array}{l}\text { Type: Miniature-adhesive mounting, Bandwidth: } 0.2 \mathrm{~Hz} \text { to } 12 \mathrm{kHz} \text {, Voltage } \\
\text { sensitivity: } 10 \mathrm{mV} / \mathrm{g} \text {, Resonant frequency: } 50 \mathrm{kHz} \text {, Amplitude response: } \\
2-10000 \mathrm{~Hz} \text {, Supply voltage: }+18 \text { to }+28 \mathrm{~V}-\mathrm{DC} \text {, Supply current: } \\
+2 \text { to }+10 \mathrm{~mA} \text {, Temperature range: }-55^{\circ} \mathrm{C} \text { to }+125{ }^{\circ} \mathrm{C}\end{array}$ \\
\hline 3 & DAQ & $\begin{array}{l}\text { Number of channels: } 4 \text { analog input channels, ADC resolution: } 24 \text { bits, Sampling } \\
\text { mode: simultaneous, Frequency: } 13.1072 \mathrm{MHz} \text {, Accuracy : } \pm 50 \mathrm{ppm} \text { max, Data } \\
\text { rate range (fs) Min: } 1.652 \mathrm{kS} / \mathrm{s} \text { Max: } 51.2 \mathrm{kS} / \mathrm{s}\end{array}$ \\
\hline 4 & Impact hammer & $\begin{array}{l}\text { Max force: } 4448 \mathrm{~N} \text {, Resonance frequency: } 50 \mathrm{kHz} \text {, Max frequency: } 8 \mathrm{kHz} \text {, Head } \\
\text { mass: } 100 \mathrm{~g} \text {, Overall length: } 223 \mathrm{~mm} \text {, Full scale output : } \pm 5 \mathrm{~V} \text {, Supply voltage: } \\
8 \text { to } 10 \mathrm{~V}-\mathrm{DC} \text {, Supply current: } 2-10 \mathrm{~mA} \text {, Sensor material: Stainless steel, Handle } \\
\text { material: Fiber glass with rubber grip, Hammer tip: Rubber, plastic, metal }\end{array}$ \\
\hline
\end{tabular}

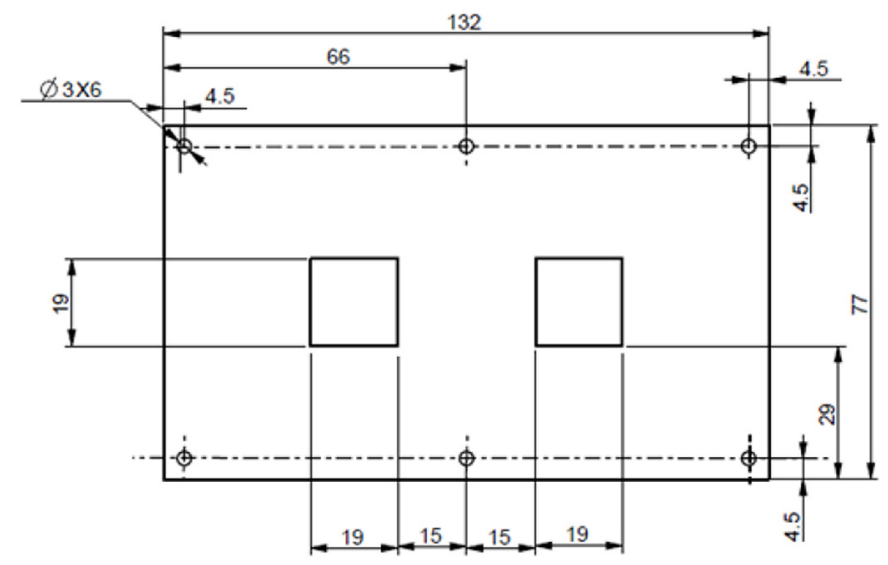

Fig. 4. Dimension details of the board.

Centre of the board whose dimensions are $19 \times 19 \mathrm{~mm}$. The dimensions of the board are as shown in Figures 4 and 5 . The PCB and chip assembly along with the solder balls is modeled in ANSYS [22]. The PCB board of dimension $132 \times 77 \times 1 \mathrm{~mm}$ is modeled initially. Only the outer 3 rows of the solder balls, along with the substrate, are modeled because during vibration loadings stress induced in the inner balls are minimum. Hence, the inner solder balls are neglected during modeling in order to reduce the complexities in the model. The connectors present in the PCB were neglected. Then the 2 chips are modeled above the solder ball. Then the top and bottom areas of the solder balls are extruded till the top and bottom area of the chip and the PCB. Then both of them are overlapped and glued. SOLID 45 element was used. The FE model is shown in Figure 6. Due to data losses importing of model from other modeling software were avoided. The material properties used is given in Table 2.

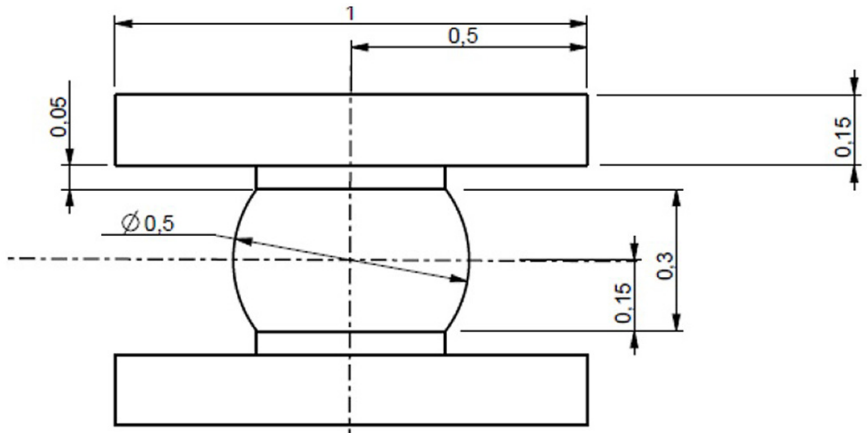

Fig. 5. Dimension details of the solder ball.

\subsection{Meshing the model}

FEA uses a complex system of points called nodes which make a grid called a mesh. This mesh is programmed to contain the material and structural properties which define how the structure will react to certain loading conditions. Nodes are assigned at a certain density throughout the material depending on the anticipated stress levels of a particular area. Regions which will receive large amounts of stress usually have a higher node density than those which experience little or no stress. Points of interest may consist of fracture point of previously tested material, fillets, corners, complex detail, and high stress areas. The mesh acts like a spider web in that from each node there extends a mesh element to each of the adjacent nodes. This web of vectors is what carries the material properties to the object, creating many elements [23,24]. A free mesh has no specified pattern applied to it and it has no restrictions in terms of the element shapes. Free meshing in volumes contain only tetrahedral element shapes, resulting in a large number of elements, whereas a mapped mesh contains 
Table 2. Properties of the components.

\begin{tabular}{lllll}
\hline Sl no. & Materials & Young's modulus $(\mathrm{Gpa})$ & Poisson's ratio & Density $\left(\mathrm{Kg} / \mathrm{m}^{3}\right)$ \\
\hline 1 & PCB & 25 & 0.27 & 3400 \\
2 & Solder ball(Sn-1Cu-1Ni-1Ag) & 49.4 & 0.27 & 7309 \\
3 & Molding component & 20.57 & 0.3 & 1880 \\
\hline
\end{tabular}

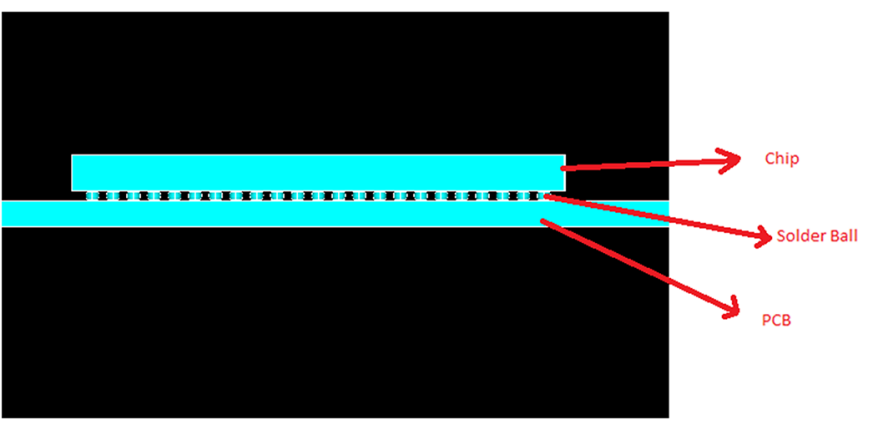

Fig. 6. Finite element model.

lower number of elements. Free meshing contains only higher order tetrahedral elements so the number of degree of freedom will be very high, while the mapped mesh has lower order elements, so the DOF will be lower [23,24]. A mapped mesh has a regular pattern, with rows of elements. Having a regular pattern with rows of elements, mapped mesh is a good choice. For this type of mesh, the model is built as a series of fairly regular volumes or areas that can accept a mapped mesh. The element shapes should have all quadrilateral or triangular for areas and all hexagonal elements (Brick) for volumes [24].

Sweep meshing is yet another option for meshing a volume. It is the process of meshing an existing volume by sweeping an area mesh [24]. Using volume sweeping, we can fill the existing unmeshed volume with elements by sweeping the mesh from a bounding area throughout the volume. Sweep mesh in the ANSYS is used for meshing the electronic package model. The FE model after meshing is shown in Figure 7. There were 83220 elements in the FE model.

\subsection{Modal analysis}

Natural frequency, also called as resonant frequency, is defined as the fundamental resonant mode of a vibrating system. It is also defined as the frequency that vibrates when a small impact load is applied for a specific period of time. During vibration test, natural frequencies and mode shapes are crucial parameters that represent the dynamic response of the test specimen. The dynamic characteristics such as natural frequency, mode shapes are identified by conducting modal analysis [25]. Modal analysis is based on the fact that the vibration response of a linear timeinvariant dynamic system can be expressed as the linear combination of a set of simple harmonic motions called the natural modes of vibration. The natural modes of vibration

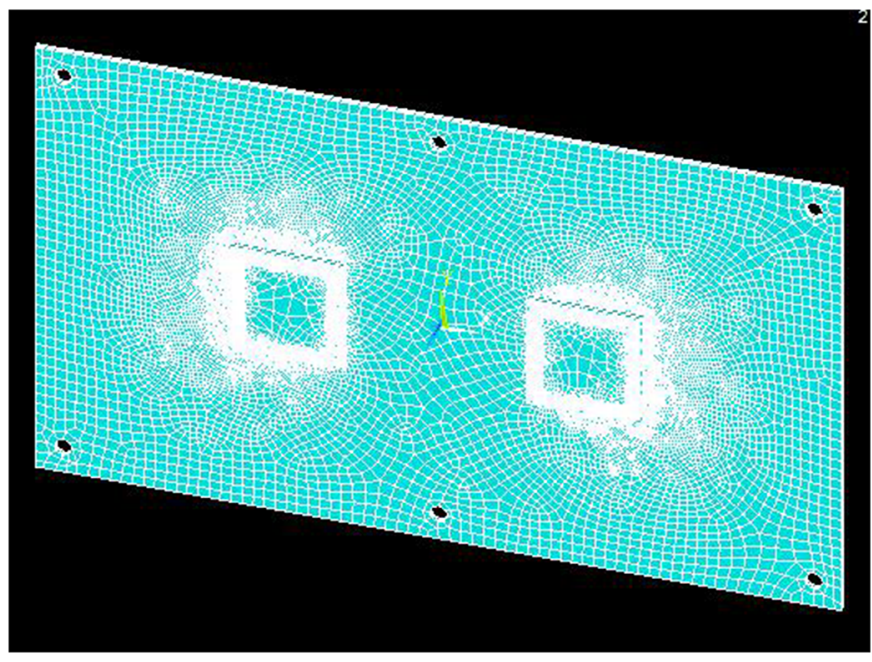

Fig. 7. Finite element model after meshing.

are inherent to a dynamic system and are determined completely by its physical properties (mass, stiffness, damping) and their spatial distributions [25]. Boundary conditions were given to the model. The 4 holes in the electronic package model were arrested for all degree of freedoms. The modal analysis was done. Natural frequencies and mode shapes were obtained

$$
[\mathrm{M}][\ddot{\mathrm{U}}]+[\mathrm{C}][\dot{\mathrm{U}}]+[\mathrm{K}][\mathrm{U}]=[\mathrm{F}]
$$

where $[\mathrm{M}]$ is the mass matrix, $[\ddot{\mathrm{U}}]$ is the second time derivative of the displacement [U] (i.e., the acceleration), $[\mathrm{U}]$ is the velocity, $[\mathrm{C}]$ is a damping matrix, $[\mathrm{K}]$ is the stiffness matrix, and $[\mathrm{F}]$ is the force vector.

For vibrational modal analysis, the damping is generally ignored, leaving only the first and third terms on the left-hand side.

$$
[\mathrm{M}][\ddot{\mathrm{U}}]+[\mathrm{K}][\mathrm{U}]=[0]
$$

This is the general form of the Eigen system encountered in structural engineering using the FEM.

\subsection{Experimental modal analysis (impact test)}

Experimental modal analysis involves modal testing, which is used to derive the modal model of a linear time-invariant vibratory system. This is based on establishing the relationship between the vibration response at one location and excitation at the same or another location as a function 

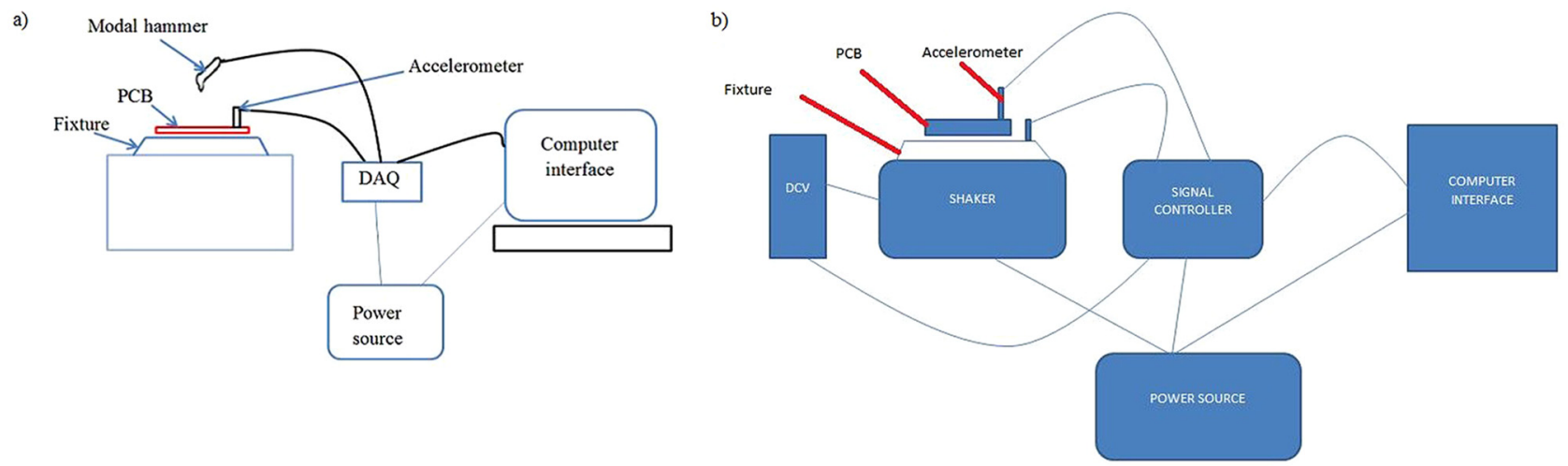

Fig. 8. Block diagram of the experimental setup. (a) Modal analysis. (b) Random vibration.

of excitation frequency. This relationship is known as Frequency Response Function (FRF) [26]. The line sketch of the impact test is shown in Figure 8a. Instruments and software used for the test are: Impact hammer, DAQ, Accelerometer, LABVIEW software.

\subsubsection{Frequency response function (FRF)}

For any measurement, noise exists at both the input and the output. For frequencies close to resonance, the vibration response is significant so noise at the output can be ignored i.e., peaks exist at natural frequencies. The FRF can be defined simply as the ratio of two Fourier transforms. The first is that of the response $x(\mathrm{t})$ and denoted as $X(\omega)$. The second is that of the input force $f(t)$ and denoted as $F(\omega)$ [27-29].

$$
H(\omega)=\frac{X(\omega)}{F(\omega)} .
$$

It represents the complex ratio between output and input, as a function of frequency $(\omega)$. By complex we mean that the function has a magnitude $[H(\omega)]$ and a phase $[\Phi(\omega)]$. The physical interpretation of the FRF is that a sinusoidal input force, at a frequency $\omega$, will produce a sinusoidal output motion at the same frequency. The output amplitude will be multiplied by $[H(\omega)]$, and the phase, between output and input, will be shifted by $[H(\omega)]$ $[28,29]$. Generally, two domains exist that are time domain and frequency domain. The input data acquired through DAQ is in time domain while FRF is a frequency domain data. Time domain curve is a random vibration curve so detecting a small change in the system becomes difficult. But in frequency domain, those changes in system can be seen. So smaller distortions in time domain data can be seen easily in frequency domain data. The time domain data is converted to frequency domain data by Fourier analysis [27-29]. LabVIEW 12.0 is used to acquire data i.e., force data from impact hammer and voltage data from accelerometer through DAQ. These data are fed as input to Dual channel FFT analyzer. From FFT, Real and imaginary plots of FRF over frequency can be obtained. Noise signal is eliminated by averaging the impacts. Plastic tip is used for impact testing. Defining sampling rate and number of samples to be measured is necessary in order to obtain data with respect to time. Sensitivity of impact hammer and accelerometer is also fed as input to LabVIEW. Circuit diagram in LABVIEW for measuring natural frequencies is shown in Figure 9. From real and imaginary plots of FRF over frequency, natural frequency can be obtained. At natural frequency, the real part goes to zero and imaginary goes to peak and it is called peak picking method. Peaks in imaginary plot indicate maximum energy to be concentrated at that frequency. So natural frequency can be obtained over the frequency range $(100-1000 \mathrm{~Hz})$ by an impact given to the PCB through Dual channel FFT analyzer.

\subsection{Random vibration analysis using FEA}

The environment where the electronic packages are working will be subjected to random vibration. In order to produce highly reliable electronic packages the manufacturers must clearly understand the vibration environment where the system is going to operate. Random vibrations are time-dependent displacements of a particle whose displacement are not repetitive in nature and it does not vary in equal intervals of time. So they are aperiodic and it consists of more than one frequency component. So the displacement with respect to time is not sinusoidal in nature. Random vibration is unique in that all of the frequencies within a given bandwidth are present all the time, and at any instant of time. This means that when an electronic system is subjected to a random vibration environment over a frequency bandwidth from 100 to $1000 \mathrm{~Hz}$, all of the structural resonances of the electronic system within the same bandwidth will be excited at the same time $[25,26]$. Random vibration environments in the electronics industry normally deal in terms of Power Spectral Density (PSD) which is measured in gravity units. The input and output response curves are typically plotted on $\log -\log$ paper, with PSD $\left(\mathrm{G}^{2} / \mathrm{Hz}\right)$ along $y$-axis and frequency $(\mathrm{Hz})$ plotted along $x$-axis [22]. According to Joint Electron Device Engineering Council (JEDEC) Vibration will be applied to the component outer surface casing or leads in a manner to simulate expected vibration during processing and packaged shipment. Selection of the 


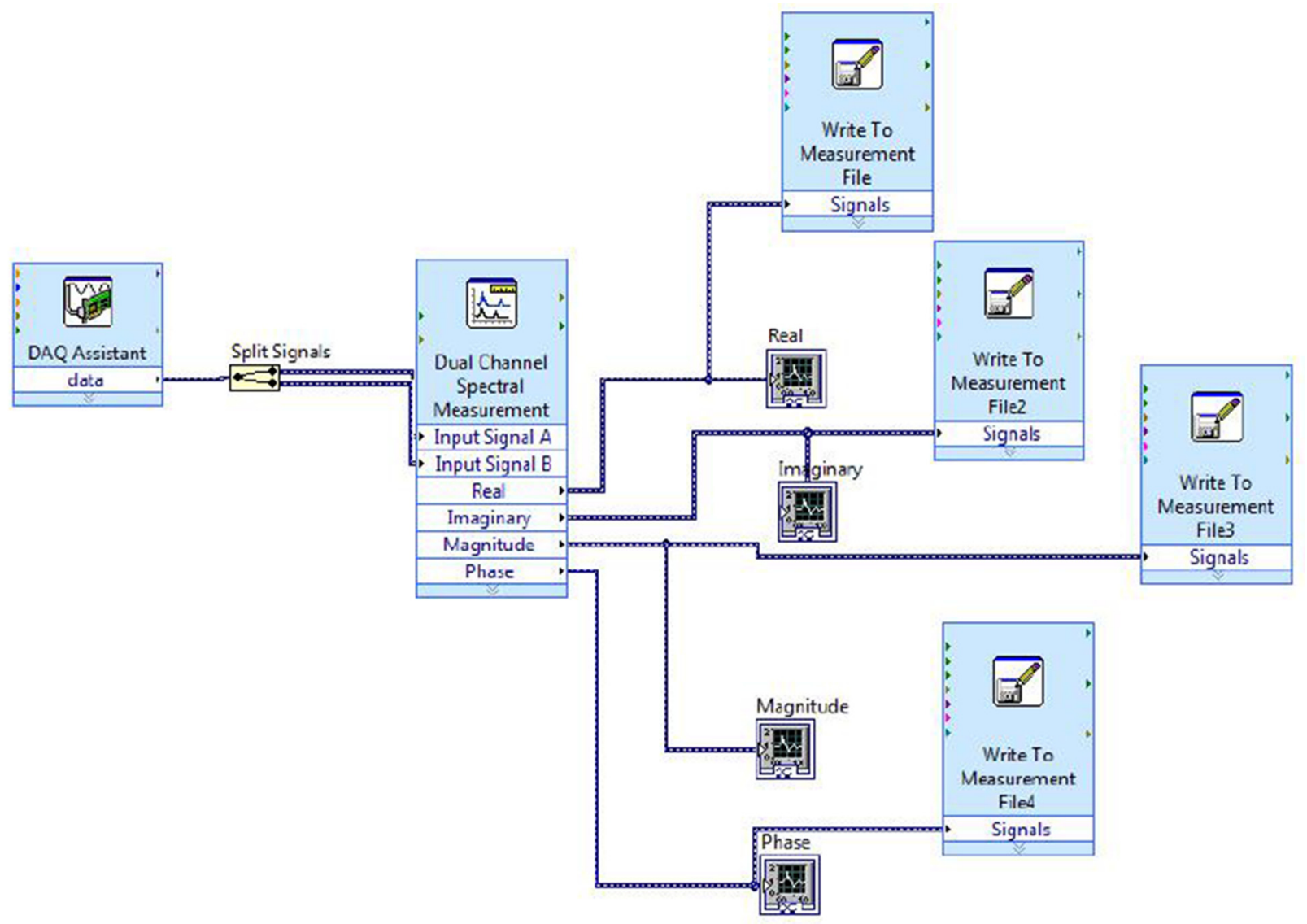

Fig. 9. Circuit diagram in LABVIEW.

appropriate test condition should be based on the actual shipping or application condition requirement for the component. The service condition must be designated, and subjected to the required test level for a minimum of $90 \mathrm{~min}$ in total, to complete all three axes. The PSD test level will be applied within a tolerance $+/-6 \mathrm{~dB}$ of the nominal values at any frequency [29]. The failure criteria is that any mechanical damage such as cracking, chipping or breaking of the package will be considered as a failure and this damage is critical to component performance in the specific application. The component test levels specified by JEDEC standards represent expected vibration during processing, shipment and various levels of application vibrations to which a component can be exposed. Selection of the appropriate test condition should be based on the actual shipping or application condition requirement for the component. The input PSD given for the experimental and finite element analysis is a white noise with a $G$ level of 0.05-0.12 $\mathrm{G}^{2} / \mathrm{Hz}$, which is an extreme condition of vibration in any application environment [29]. Random vibration analysis is a form of spectrum analysis. Spectrum is a graph of spectral value versus frequency that captures intensity and frequency content of time history loads. Random vibration analysis uses PSD to quantify the loading. Mathematically, the area under a PSD-versusfrequency curve is equal to the variance, which is square of
Table 3. Input PSD.

\begin{tabular}{ll}
\hline Frequency $(\mathrm{Hz})$ & Input PSD $\left(\mathrm{G}^{2} / \mathrm{Hz}\right)$ \\
\hline 100 & 0.05 \\
1000 & 0.05 \\
\hline
\end{tabular}

the standard deviation of the response. The random vibration analysis is done using ANSYS [28,29]. Input PSD is given in Table 3. Input PSD given at 4 holes is shown in Figure 10 .

\subsection{Experimental random vibration analysis}

Experimental random vibration analysis is done in order to validate the finite element spectrum analysis. The experiment is carried out by giving random vibration inputs to the PCB by means of an electro dynamic exciter. Random excitation waveforms are generated electronically, or digitally synthesized, and fed to a power amplifier driving an electrodynamic vibration shaker. This excitation is random and continuous in time with a finite record length. For response measurement from the PCB any of the motion parameters - displacement, velocity, or acceleration - can be measured. Piezoelectric accelerometers are used to 


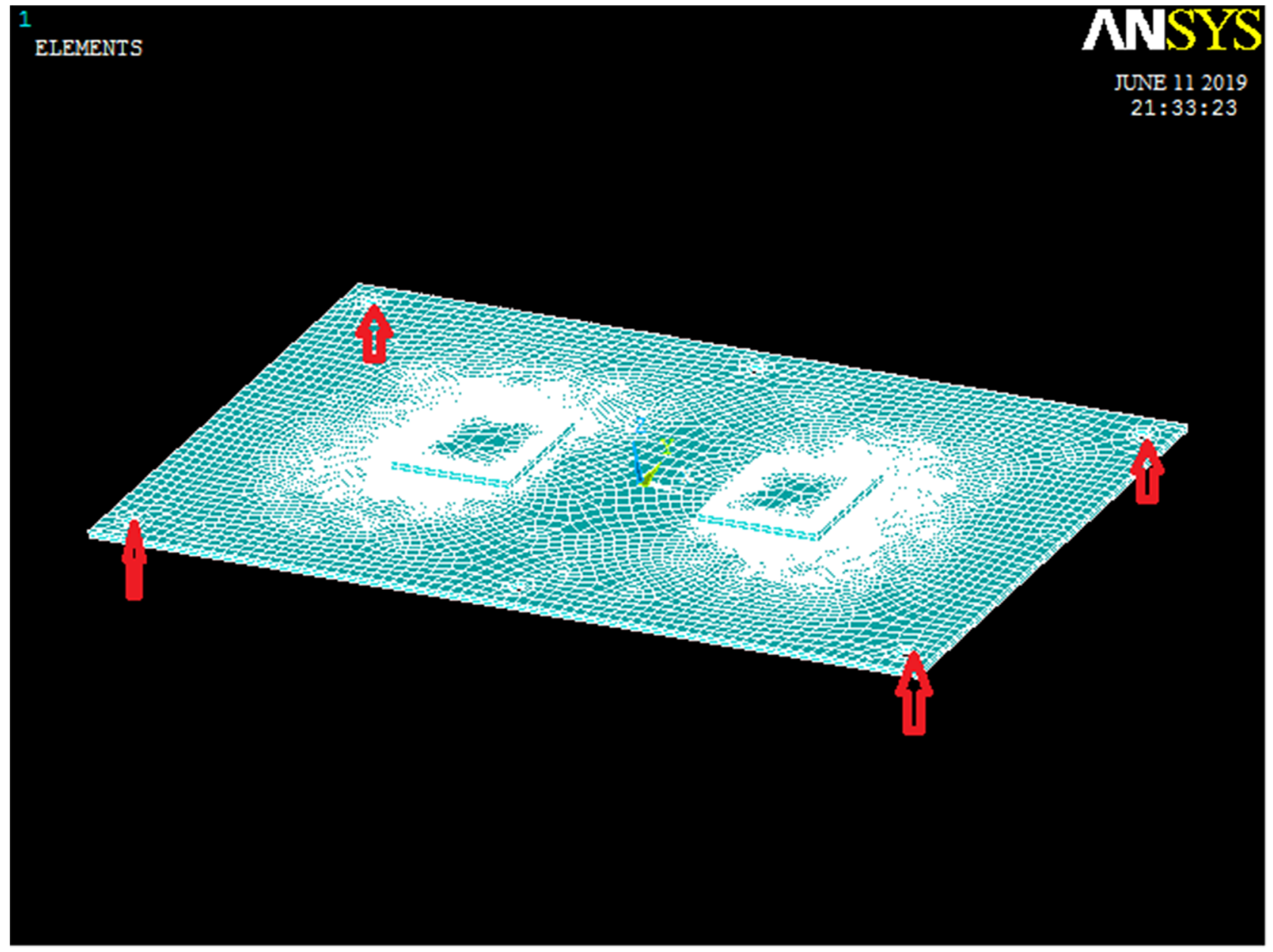

Fig. 10. Input PSD given at 4 holes.

measure the response because it offers good linearity, low weight, simple mounting methods, and has a wide frequency range. One accelerometer is mounted on the fixture base plate to control and monitor the input signals. Other is a miniature accelerometer mounted on the PCB to monitor the output signals. Accelerometers are then connected to a coupler, to convert the voltage signals into charge signals. Then the charge signals are passed into a signal conditioner through which the signals are transferred to the computer. Block diagram of the experimental setup is given in Figure $8 \mathrm{~b}$. The electronic package mounted on the shaker with a fixture is shown in Figure 11. In order to control and monitor the input and output PSD curves, respectively, Sine vibration controller software is used. The control parameters are set in the software by giving the type of random vibration, frequency range line combinations and the test duration. Then the sensitivities of the accelerometers are filled in the channel table. The safety parameters for the vibration input is given as per the JEDEC standards. The input PSD curve is given as a white noise with the $\mathrm{G}$ value as $0.05 \mathrm{G}^{2} / \mathrm{Hz}$, which is same as that given in the finite element analysis. After checking for the loop, the main test is started. The gain is given in the power amplifier and shaker is set to vibrate. The response acceleration PSD of the PCB is monitored through the software [23,24,27-30].

\section{Results and discussions}

\subsection{Finite element modal analysis results}

Modal analysis is conducted using a finite element model. The results of the modal analysis are shown in Table 4. Five natural frequencies can be observed from Table 4. Mode shapes of these corresponding modes are obtained and are shown in Figure 12.

\subsection{Experimental modal analysis results}

Using the experimental setup which were previously explained, experimental modal analysis was conducted and the results were noted down. A comparison of the finite element analysis results and the experimental results are shown in Table 5. It can be concluded that the FEA results were validated with the experimental results. The FE model can therefore be used in the further analysis. Real 


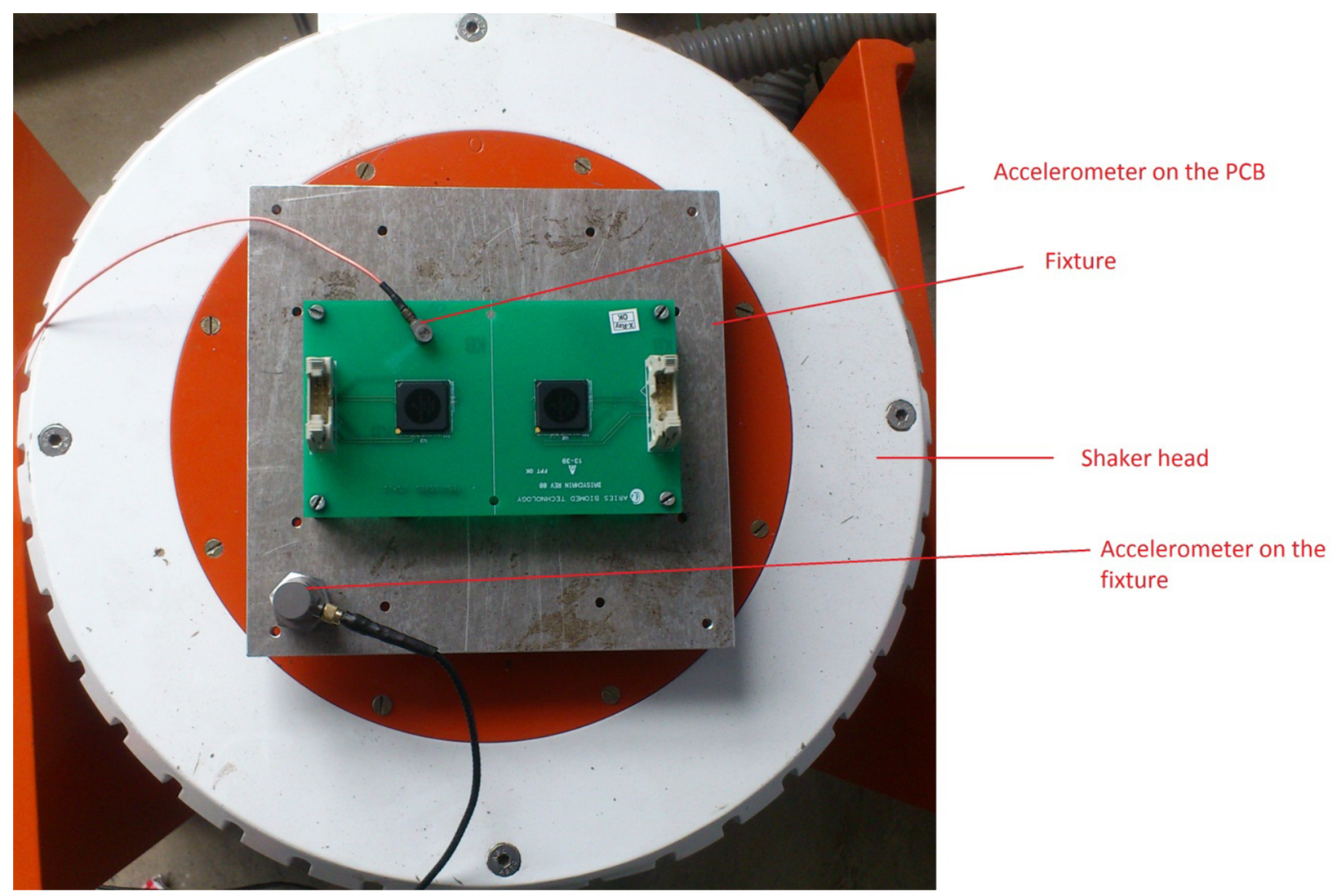

Fig. 11. The electronic package mounted on the shaker with a fixture.

Table 4. Modal analysis results obtained from FEA.

\begin{tabular}{ll}
\hline Mode No & Natural frequency $(\mathrm{Hz})$ \\
\hline 1 & 155.17 \\
2 & 308.25 \\
3 & 432.66 \\
4 & 599.50 \\
5 & 666.08 \\
\hline
\end{tabular}

part and imaginary part of FRF indicating the natural frequencies is shown in Figure 13.

\subsection{Random vibration analysis results using FEA}

Once the PSD input is given, the participation factors and controls for the specified PSD table are calculated. Then the model is solved and the modes are combined. 1 sigma stresses are read from the load step 3. 1sigma stresses represent that the stress level is at or below $1 \mathrm{~s} 68.2 \%$ of the time. Von-misses stress results plotted are shown in Figure 14. From which the maximum stress is found to be $12.8 \mathrm{MPa}$ which is located at a corner solder ball in the chip as shown in Figure 14. The response stress PSD is calculated from the element that has maximum von-misses stress results. In another previous study, vibration durability model constants for SAC305 and Sn37Pb solder materials were extracted from harmonic vibration test results of LCR assemblies [30]. The extracted durability models were used to predict the fatigue life of LCR assemblies under broadband, step-stress vibration excitation. Increasing the hardening exponent for SAC material from 0.2 to 0.28 (40\%) reduced the prediction for center LCR2512 interconnects about four times. Reducing the Young's modulus from 47.5 to $18 \mathrm{GPa}$ did not produce any significant changes in the durability prediction [30]. Figure 14 shows stress distribution on the corner solder ball.

\subsection{Experimental random vibration results}

The FEA results using the PSD analysis in the ANSYS have been validated with experiment results. During FEA analysis the maximum stress was found to be at corner solder joint. Experiment results show that the corner solder joint failed first. This is shown in Figure 15. From Figure 15, it is clear that the corner solder ball fails first. This prediction obtained in the finite element analysis is validated using the experiments. This information is vital in the design procedure since the failure location can be incorporated as a factor in the design modifications. 


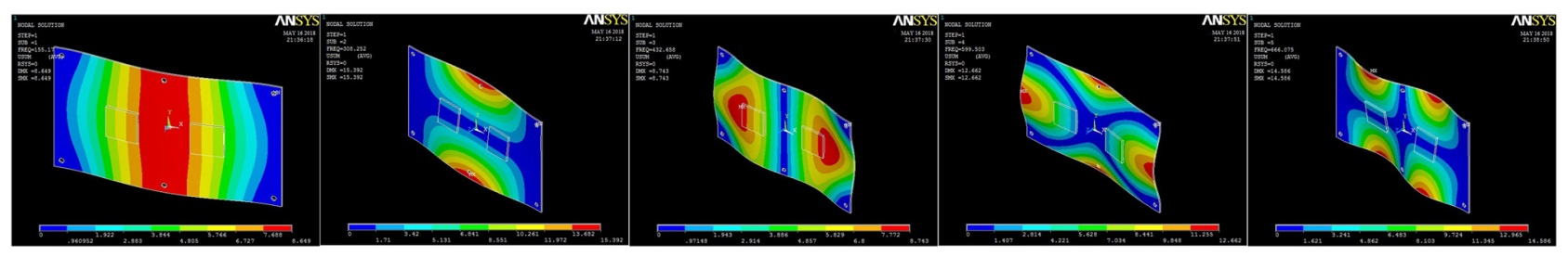

Fig. 12. Mode shapes of the corresponding modes.

Table 5. Comparison of the natural frequencies obtained through FEA and experiment.

\begin{tabular}{llll}
\hline Mode No & Natural frequency from FEA $(\mathrm{Hz})$ & Natural frequency from modal test $(\mathrm{Hz})$ & Error $(\%)$ \\
\hline 1 & 155.17 & 161 & 3.62 \\
2 & 308.25 & 306 & -0.74 \\
3 & 432.66 & 411 & -5.27 \\
4 & 599.50 & 573 & -4.62 \\
5 & 666.08 & 628 & -6.06 \\
\hline
\end{tabular}
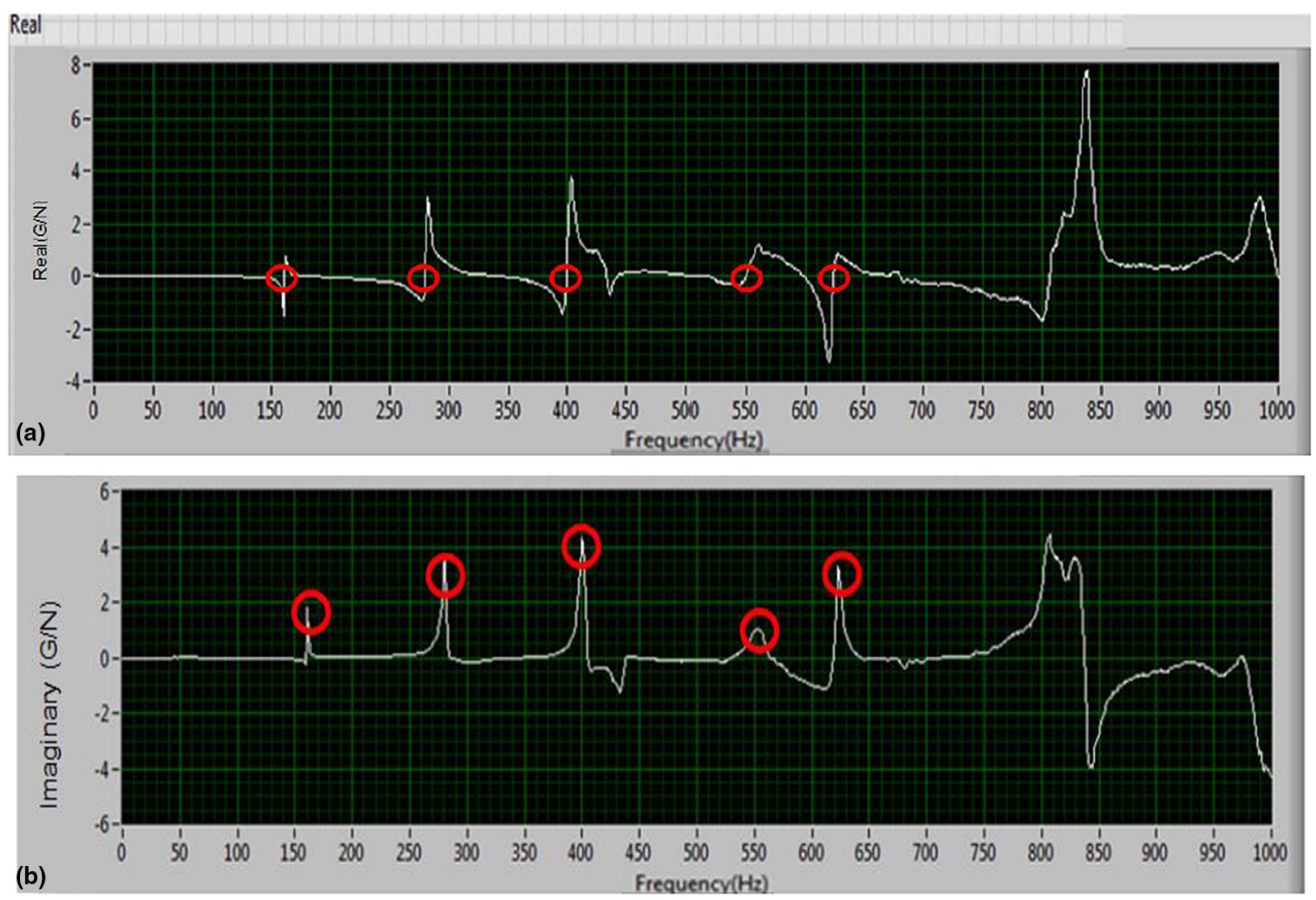

Fig. 13. (a) Real part of FRF indicating the natural frequencies. (b) Imaginary part of FRF indicating the natural frequencies.

\subsubsection{Failure of the solder ball}

The experiments were conducted for $102 \mathrm{~min}$ and it was found that the solder ball at the corner was failed. After the random vibration experiment, the solder balls of the electronic package are viewed under the tool maker microscope under $30 \times$ magnification. It is found that the corner solder ball of the package has been failed during the random vibration which is shown in the figure, the crack in the solder balls are viewed under scanning electron microscope (SEM). The images are given in Figure 16. 


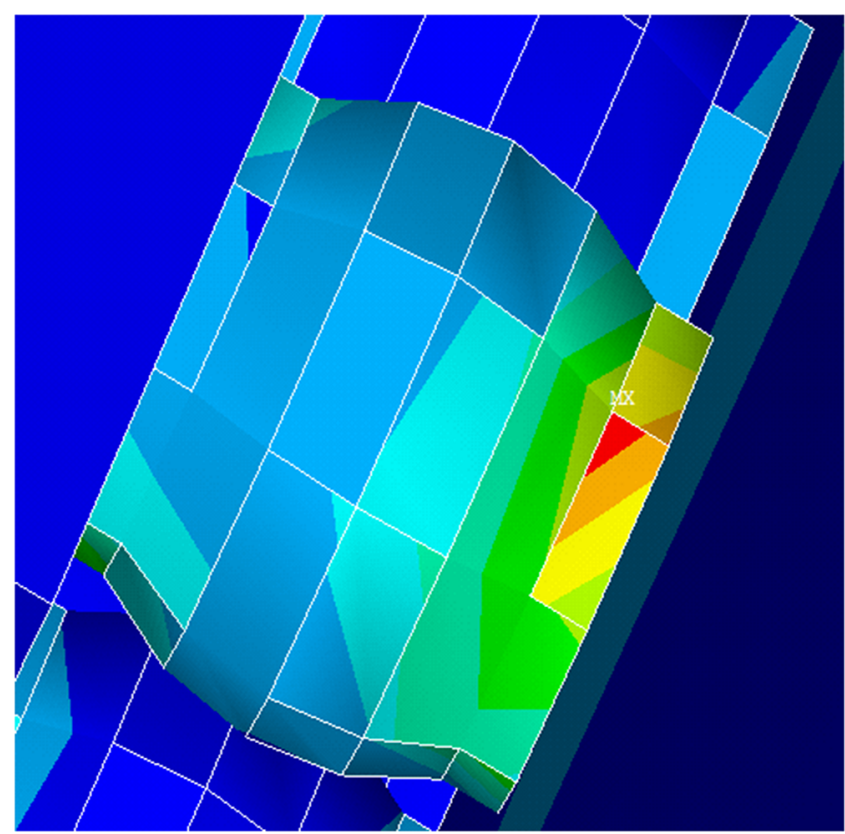

Fig. 14. Stress distribution on the corner solder ball.
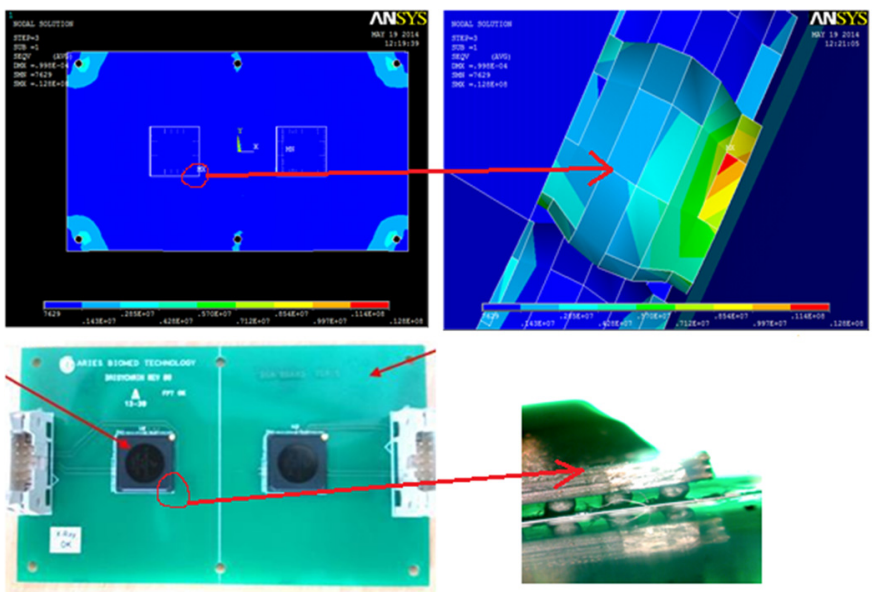

Fig. 15. Failure of solder joint obtained from FE results and experiment.
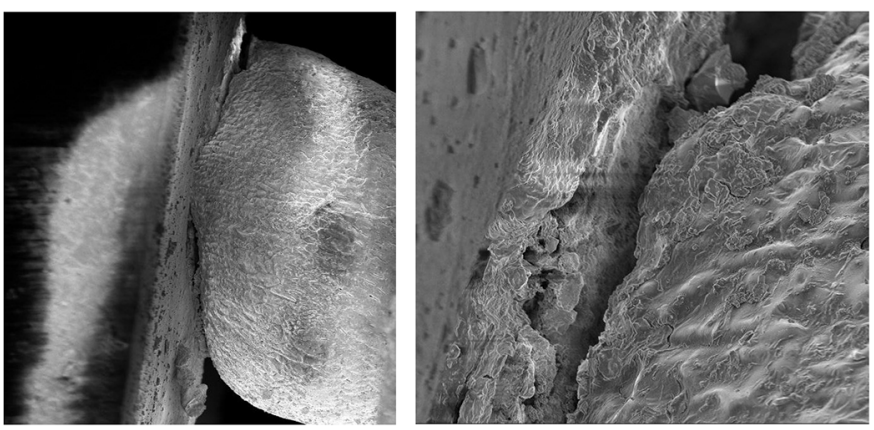

Fig. 16. SEM image of the corner solder ball of the package failed.

\section{Conclusion}

This paper investigated the effect of random vibration in electronic package soldered using lead-free solder alloy $\mathrm{Sn}-1 \mathrm{Cu}-1 \mathrm{Ni}-1 \mathrm{Ag}$. Finite element model was created using ANSYS software. Modal analysis was done using Finite element method. The same was validated by conducting experimental modal analysis test (impact test). Random vibration tests were conducted with white noise PSD acceleration amplitude as the input. The same FE model was applied to run the spectrum analysis to determine the response spectrum of the critical solder joint. The volume averaged PSD was calculated from the response PSD. The random vibration results validated the point made in the FE results that the first failure of the solder balls will be at the corner solder ball position. The maximum stress noted was $12.8 \mathrm{MPa}$. Combining with the mechanical properties observed for the $\mathrm{Sn}-1 \mathrm{Cu}-1 \mathrm{Ni}-1 \mathrm{Ag}$ [21], the new solder alloy can be considered as a promising replacement for the $\mathrm{Sn}-\mathrm{Pb}$ solder alloy.

The effect of random vibration on the micro-solder joints when the electronic parts are becoming smaller can be considered as a future research work. The transistor density increases and this change need to be incorporated with micro-solder alloys.

\section{References}

1. M.M. Schwartz, Soldering: understanding the basics, 1st edn. (ASM International, USA, 2014)

2. H.H. Manko, Solder and Soldering, 2nd edn. (McGraw-Hill, New York, 1979)

3. European Parliament. Proposal for a Directive of the European Parliament and of the Council on Waste Electrical and Electronic Equipment and on the restriction of the use of certain hazardous substances in electrical and electronic equipment. COM 2000:347

4. S. Cheng, C.-M. Huang, M. Pecht, A review of lead-free solders for electronics applications. Microelectron. Reliab. 75, 77 (2017)

5. A.K. Gain, L. Zhang, Growth mechanism of intermetallic compound and mechanical properties of nickel (Ni) nanoparticle doped low melting temperature tin-bismuth (Sn-Bi) solder, J. Mater. Sci. Mater. Electron. 27, 781-794 (2016)

6. A.K. Gain, Y.C. Chan, K.C. Yung, A. Sharif, L. Ali, Effect of nano $\mathrm{Ni}$ additions on the structure and properties of Sn-9Zn and $\mathrm{Sn}-\mathrm{Zn}-3 \mathrm{Bi}$ solders in $\mathrm{Au} / \mathrm{Ni} / \mathrm{Cu}$ ball grid array packages, Mater. Sci. Eng. B 162, 92-98 (2009)

7. S.K.K.W.M. Chen, C.R. Kaoa, Effects of Ti addition to Sn-Ag and Sn-Cu solders, J. Alloys Compd. 520, 244-249 (2012)

8. Y.S. Chen, C.S. Wang, Y.J. Yang, Microelectron. Reliab. 48, 638-644 (2008)

9. R.S. Li, A methodology for fatigue prediction of electronic components under random vibration load, J. Electron. Packag. 123, 394 (2001)

10. M. Kirs et al., Application of HOHWM for vibration analysis of nanobeams, Key Eng. Mater. 799, 230-235 (2019)

11. D.H. Bassir, J.L. Zapico, M.P. González, R. Alonso, Identification of a spatial linear model based on earthquakeinduced data and genetic algorithm with parallel selection, Int. J. Simul. Multidisci. Des. Optim. 1, 39-48 (2007) 
12. R. Chaari, M. Abennadher, J. Louati, M. Haddar, Mathematical methodology for optimization of the clamping forces accounting for workpiece vibratory behavior, Int. J. Simul. Multisci. Des. Optim. 5, A13 (2014)

13. T. Liu, J.-H. Zhu, F. He, H. Zhao, Q. Liu, C. Yang, A MAC based excitation frequency increasing method for structural topology optimization under harmonic excitations, Int. J. Simul. Multisci. Des. Optim. 8, A4 (2017)

14. R.R. Schaller, Moore's law: past, present and future, IEEE Spectr. 34, 52-59 (1997)

15. B.M. Guenin, R.C. Marrs, R.J. Molnar, Analysis of a thermally enhanced ball grid array package, IEEE Trans. Compon. Packaging Manuf. Technol. 18, 749-757 (1995)

16. C.H. Zhong, S. Yi, Solder joint reliability of plastic ball grid array packages, Solder. Surf. Mount Technol. 11, 44-48 (1999)

17. Y. Jiang, H. Li, G. Chen et al., Electromigration behavior of $\mathrm{Cu} / \mathrm{Sn} 3.0 \mathrm{Ag} 0.5 \mathrm{Cu} / \mathrm{Cu}$ ball grid array solder joints, J. Mater. Sci. Mater. Electron. 30, 6224-6233 (2019)

18. J.X. Wang, Green Electronics Manufacturing, Chap. 8, 1st edn. (CRC Press, Raton, 2012)

19. L. Bai, X. Yang, H. Gao, A novel coarse-fine method for ball grid array component positioning and defect inspection, IEEE Trans. Ind. Electron. 65, 5023-5031 (2018)

20. S. Jayesh, J. Elias, Met. Mater. Int. (2019). DOI: https://doi. org/10.1007/s12540-019-00305-3
21. S. Jayesh, J. Elias, Experimental investigations on the effect of addition of $\mathrm{Ag}$ into ternary lead free solder alloy $\mathrm{Sn}-1 \mathrm{Cu}-$ 1Ni, Lett. Mater. 9, 239-242 (2019)

22. T. Stolarski, Y. Nakasone, S. Yoshimoto, Engineering Analysis with ANSYS Software, 2nd edn. (Butterworth Heinmann, USA, 2018)

23. G. Yagawa, T. Furukawa, Recent developments of free mesh method, Int. J. Numer. Meth. Eng. 47, 1419-1443 (2000)

24. D.S.H. Lo, Finite element mesh generation (CRC Press, Bocs Raton, 2018)

25. S.A. Mitchell, Choosing corners of rectangles for mapped meshing (ACM, New York, 1996)

26. J. He, Z.-F. Fu, Basic vibration theory, in: Modal Analysis (Butterworth-Heinemann, Oxford, 2001), pp. 49-78

27. J. He, Z.-F. Fu, Frequency response function measurement, in: Modal Analysis (Butterworth-Heinemann, Oxford, 2001) pp. $140-158$

28. Y. Cinar, G.J. Jang, Mech. Sci. Technol. 28, 107 (2014)

29. P. Lall, S. Gupte, P. Choudhary, J. Suhling, Solder joint reliability in electronics under shock and vibration using explicit finite-element submodeling, IEEE Trans. Electron. Packag. Manuf. 30, 74-83 (2007)

30. Y. Zhou, M. Al-Bassyiouni, A. Dasgupta, Harmonic and random vibration durability of SAC305 and $\mathrm{Sn} 37 \mathrm{~Pb}$ solder alloys, IEEE Trans. Compon. Packaging Technol. 33, 319$328(2010)$

Cite this article as: S. Jayesh, Jacob Elias, Finite element modeling and random vibration analysis of BGA electronic package soldered using lead free solder alloy - Sn-1Cu-1Ni-1Ag, Int. J. Simul. Multidisci. Des. Optim. 10, A11 (2019) 